\title{
Study of Comprehensive Geriatric Care in Sharkia Governorate
}

\author{
Mohammed Nabil Mahmoud Abo-Elela, Osama Abdel-Aziz Mohammed Fakher, \\ Mahmoud Elsayed Abd-Elaty ${ }^{*}$ \\ Department of Community Medicine and Industrial Medicine, Faculty of Medicine, Al-Azhar University, Cairo, Egypt
}

Email address:

Ramyelsayed83@gmail.com (M. E. Abd-Elaty)

${ }^{*}$ Corresponding author

\section{To cite this article:}

Mohammed Nabil Mahmoud Abo-Elela, Osama Abdel-Aziz Mohammed Fakher, Mahmoud Elsayed Abd-Elaty. Study of Comprehensive Geriatric Care in Sharkia Governorate. Journal of Family Medicine and Health Care. Vol. 3, No. 4, 2017, pp. 63-74.

doi: $10.11648 /$ j.jfmhc.20170304.11

Received: October 10, 2017; Accepted: October 23, 2017; Published: November 15, 2017

\begin{abstract}
Background: In recent years, there has been a sharp increase in the number of older persons all over the world. The number of people aged 60 years and over is expected to increase to 2 billion by the year 2050. One of the greatest challenges in geriatrics is the provision of optimal comprehensive geriatric care for older adults. Family physicians can improve the early identification of specific problems that are common in the elderly and also shift their focus from disease specific intervention to preventive care. Objectives: To improve the health of geriatrics through identifying health problems among the studied geriatric population in Sharkia governorate and determining the level of the family physicians' knowledge and practice of comprehensive geriatric care in Sharkia governorate. Subjects and methods: A cross-sectional study was conducted, it was conducted in 9 accredited family health centers in Sharkia governorate for one year. The family health centers were selected by stratified random sampling technique from health centers of Sharkia governorate. The sample included 630 elderly person and 52 family physicians. Results: The results of this study declared that the most prevalent selfreported morbidities were, diabetes mellitus $(36.7 \%)$, hypertension $(33.5 \%)$ and respiratory disease $(20.2 \%)$. The results also showed that $(76.9 \%)$ of the studied family physicians have adequate knowledge about physical problems of the elderly population and $(25 \%)$ of the studied family physicians have adequate performance in taking personal history, abdominal examination and counseling of the elderly population. Conclusion: The more prevalent self-reported morbidities among the studied geriatric population were, diabetes mellitus, hypertension and respiratory diseases. Most of family physicians had inadequate level of performance as regard physicians performance during dealing with geriatric patients. Recommendations: The study highlighted the need to promote geriatric health care services, regular health checkup and social support by people. Continuous training of family physicians specially in comprehensive geriatric care for providing high quality of care for elderly population.
\end{abstract}

Keywords: Comprehensive Geriatric Care, Geriatric Problems, Family Physicians

\section{Introduction}

In recent years, there has been a sharp increase in the number of older persons allover the world. Between 2000 and 2050 , the proportion of the world's population over 60 years will double from about $11 \%$ to $22 \%$. The number of people aged 60 years and over is expected to increase from 605 million to 2 billion over the same period. Most of this increase is occurring in less developed countries where the number of older people will rise from 400 million in 2000 to 1.7 billion by 2050 . This population aging can be seen as a success story for public health policies and for socioeconomic development, but it also challenges society to adapt, in order to maximize the health and functional capacity of older people as well as their social participation and security [1].

One of the main features of age of the Egyptian population over the last few decades is the gradual increase in the numbers of older people. This trend will continue over the 
next decades. There are currently 4100000 persons aged 65 years over representing $4.7 \%$ of the total population. The Expected Percentage of older people may reach $10.9 \%$ in 2026 [2].

Certain diseases are more frequent among elderly than the young people, degenerative disease of heart and blood vessels, cancer, accidents, diabetes, hypertension, disease of the locomotor system, respiratory illness and genitourinary tract disease. Even in poor countries, older people die of noncommunicable diseases, rather than from infectious diseases [3].

Evaluation of the morbidity profile among elderly people and the impact of chronic conditions and co-morbidity on functional disability and psychological wellbeing are required for better understanding of the relation between perceived health, chronic disease and disabling conditions. Assessment of the morbidity profile will help in the application of interventions, to improve the health status and the quality of life of the elderly [4].

Older adults may present with multiple problems or in an atypical fashion with functional, cognitive or social problems. A failure to adequately recognize and assess these problems in elderly patients may lead to unnecessary disability [5].

One of the greatest challenges in geriatrics is the provision of optimal care for older adults with multi-morbidity which is associated with higher rates of disability and poorer quality of life [6].

Family physicians can improve the early identification of specific problems that are common in the elderly and also shift their focus from disease specific intervention to preventive care [7].

Increase the number of older people will require that family physicians become increasingly knowledgeable about the needs of geriatric patients [8]. Approximately one-half of the ambulatory primary care for adults older than 65 years is provided by family physicians [9].

The geriatric assessment differs from a typical medical evaluation by including nonmedical domains; by emphasizing functional and psychological domains. This type of assessment often yields a more complete and relevant list of medical problems, functional problems, and psychosocial issues [10].

The comprehensive geriatric assessment is a multidimensional, multidisciplinary assessment designed to evaluate an older person's functional ability, physical health, cognition, mental health, and socio-environmental circumstances. The geriatric assessment aids in the diagnosis of medical conditions; development of treatment and followup plans [11].

Rational

Based on the previously mentioned facts;

Studying of comprehensive geriatric care is very important to improve health of elderly population throughidentifying health problems among the studied geriatric population in Sharkia governorate and determining the level of the family physicians' knowledge and practice of comprehensive geriatric care in Sharkia governorate.

\section{Subjects and Methods}

This study was carried out to study health problems of geriatrics and to assess the role of family physicians in providing comprehensive geriatric care in family health centers in Sharkia governorate. A review of literature was conducted, in order to help in the proper understanding, identify and prepare research tools.

A survey of literature was based on:

- World Health Organization publications.

- Reports from Ministry of Health in Egypt and Health Directory in Sharkia governorate.

- The periodical medical journals.

- Text books.

- Previous researches.

- Some sites from internet

\subsection{Research Strategy}

Research design:

A cross-sectional study was conducted in carrying out the research.

Research setting:

This research was conducted in 9 accredited family health centers in Sharkia governorate.

Sampling technique:

A multi stage stratified random sample technique were used to choose the family health centers. According to health directory of Sharkia governorate 2015, Sharkia health directory consists of 17 health district. We randomly selected a sample of $20 \%$ of Sharkia health districts to choose the first stage sample which resulted in choosing the following 4 health districts:

1) Zagazig health district

2) Hehia health district

3) Quenayat health district

4) Abu Hammad health district

Then we randomly selected a sample $20 \%$ of the accredited family health centers from each selected health district to choose the second stage sample

\subsection{Research Subjects}

All population aged 60 years and more attending the chosen family health centers during the time period between the first of March 2016 and the end of February 2017 were included in the study.

All family physicians working in the chosen family health centers during the period between the first of March 2016 and the end of February 2017 were included in the study.

1. Inclusion criteria:

-Regarding geriatric population:

All subjects aged 60 years and above attending the chosen family health center during the period of the study and can answer the questions of the study.

-Regarding family physicians:

All family physicians working in the chosen family health centers during the period of the study

2. Exclusion criteria: 
-Regarding geriatric population:

Elderly population who cannot communicate with others.

-Regarding family physicians:

General practitioners working in the chosen family health centers

\subsection{Methods of the Study}

Data collection tool:

For geriatric population data were collected by the following:

A structured interview questionnaire was designed to cover a variety of items such as:

a. Socio demographic data of the elderly: name, sex, age, education, marital status, residence and smoking habits.

b. Chronic disease: presence of any self-reported chronic disease diagnosed by physicians or any current chronic medication.

c. Depression: through screening of depression symptoms by using patient health questionnaire (PHQ-9). It is composed of 9 items each representing one of the criteria of depression. It uses 4 point scale; "not at all", "some days", "more than half of the days", or nearly "every day". The maximum possible score for the PHQ-9 is 27, with a cutoff of 5 to indicate the presence of at least mild depression. It includes:-

1- Lack of interest

2- Depressed mood

3- Sleep difficulties

4- Tiredness

5- Appetite problems

6- Self negative feelings

7- Concentration problems

8-Psychomotor agitation/retardation

9- Suicidal ideation

For family physicians data were collected by the following:

A structured questionnaire was designed for family physicians from the standard of ministry of health and population practice guidelines for family physicians [12].

It was designed by the researcher and self-administered by physicians. It includes the following items:

a. Personal and educational data of the studied family physicians: Name, age, sex, duration of practice, post graduate training, period of experience in family medicine and post graduate studies.

b. Questions to test the knowledge of the doctor about:

1) Items in the main topics of geriatric problems that should be assessed (the highest score of these items is 3$)$.

2) The most common physical problems that the elderly may suffer from (the highest score of these items is 4).

3) The forms of elderly abuse (the highest score of these items is 3).

4) Factors that related to nutritional problems of the elderly (the highest score of these items is 2).

5) The time that the assessment of the elderly should be routinely done (the highest score of these items is 1).

6) The information that should be included in the health records (the highest score of these items is 4).

7) The services that should be provided for the elderly at the family health center (the highest score of these items is 1).

8) Basic activities of daily living (BADL) (the highest score of these items is 1).

9) Instrumental activities of daily living (IADL) (the highest score of these items is 1).

10)The most common psychological problem in the elderly people (the highest score of these items is 4)

11)The vaccines that are recommended to the elderly.(the highest score of these items is 2)

12)Some issues that should be covered by health education programs for the elderly (the highest score of these items is 3)

13)Causes of poor compliance in elderly(the highest score of these items is 4)

14)Causes of adverse reaction to drugs in elderly (the highest score of these items is 1)

15)Drugs which predispose to fall in elderly (the highest score of these items is 2)

16)Drugs which predispose to bleeding in elderly (the highest score of these items is 2)

c. Scoring of physician knowledge:

The highest scoring degree is 38 according to the previously listed questions and the lowest degree is 0 .

Physician will be considered of having:

1. Adequate knowledge in geriatric care if the score equals to $50 \%$ or more ( $\geq 19$ degrees).

2. Inadequate knowledge in geriatric care if the score is less than $50 \%$ ( $<19$ degrees).

An observational check list was prepared by researcher from the standard of ministry of health and population practice guidelines for family physicians [12].

The observational check lists were filled by the researcher by observing the performance of each physician included in the study during handling with elderly population attending the chosen family health centers.

By observational check list of some items reflect the ideal performance of the doctors to provide geriatric care services of high quality, it includes:

1. Taking detailed history from the geriatric patient about the following items (Personal history, past history, present history, family history and dietary history ) (The highest score of these items is 22 )

2. Functional status assessment. (The highest score of these items is 9 )

3. Mental and psychological status assessment. (The highest score of these items is 1 )

4. Perfect examination of geriatric patient (Physical examination, conducts head to toe examination, abdominal examination). (The highest score of these items is 17)

5. Immunization status assessment. (The highest score of these items is 1 )

6. Communication with elderly through the procedure and gives feedback on findings of physical and any other 
procedures done. (The highest score of these items is 1)

7. Identified and recorded risk factors in customer file. (The highest score of these items is 1)

8. Drug prescription to the geriatric patient from the health unit or described from outside.(The highest score of these items is 3)

9. Does the doctor give the geriatric patient health education about his needs. (The highest score of these items is 1)

10. Does the doctor give the geriatric patient health education about other health related issues. (The highest score of these items is 1)

11. Assessment of counseling skills and communication skills and the relationship with the client. (The highest score of these items is 18 )

Scoring of performance:

If the item is performed in correct manner by the doctor, he is given the total score of all items and the highest scoring degree is 74 , and if not done at all or not done well his score is zero.

The level of quality of performance of the doctor for each item was calculated and they were divided according to their score to:

1. Adequate performance: if his score equal to $50 \%$ or more ( $\geq 37$ degrees).

2. Inadequate performance: if his score is less than $50 \%$

3. $(<37$ degrees $)$.

\subsection{Phases of the Study}

Preparatory phase:

Pre-test (Pilot) study:

The pilot study was carried out at January 2016. It was conducted on 30 elderly subjects and on 10 family physicians They were excluded from the main study sample. Data obtained from the pilot study were analyzed, and accordingly necessary modifications were done.

The aim of pilot study:

1. To formulate the final form of the research tools

2. To determine the time needed to conduct an interview.

3. To assess subject's impression, reaction and cooperation with the study

Implementation phase:

The actual fieldwork started at the beginning of March 2016, and was completed by the end of February 2017. It was done two day per week (Saturday and Tuesday, then in the next week Sunday and Wednesday, then in the next week Monday and Thursday and so on) from 9 a.m. to 2 p.m. In each one of these days, a different family health center from the selected centers was visited.

For geriatric population, the questionnaires were filled by the researcher through personal interview. The objectives of the study were explained to each participant before filling the questionnaire.

For family physicians, the researcher collected the questionnaires by meeting the family physicians working in the chosen family health care units after explaining to them the objectives of the study.

The researcher completed the check list of performance of family physicians by observation of the performance of the family physicians while handling with elderly population attending the chosen family health centers.

Evaluation phase:

Data processing:

* Variables were coded for proper extraction of data.

* Data entry was carried out using SPSS \{Statistical Package for Social Science $\}$ computer software program version 20.

Statistical analysis of data:

The collected data were statistically managed as follows:

* Descriptive statistics:

1. The mean was used as a measure of central tendency.

2. The standard deviation was used as a measure of dispersion.

* Analytic statistics:

1. Categorical data were compared by using chi square test.

2. Probability was considered significant if P-value is less than or equal to 0.05 .

Presentation of data:

- Microsoft word and excel programs have been used to formulate tables.

Reporting phase:

- All other phases of thesis were completed in this phase including discussion, conclusions, recommendations and summary.

- The current thesis was reviewed, corrected and typed in the final form.

\subsection{Time Table of the Study}

$\begin{array}{lll}\text { Time } & \text { Period } & \text { Topic } \\ \text { 10-11-12/2015 } & 3 \text { months } & \text { Review of literature } \\ \text { 1-2/2016 } & 2 \text { month } & \text { Design of study tools and pilot study } \\ \text { 3/2016 to the end of } & 12 & \\ \text { 2/2017 } & \text { months } & \text { Collection of data } \\ \text { 3-4/2017 } & 2 \text { month } & \text { Data entry and organization } \\ 5-6 / 2017 & 2 \text { month } & \text { Statistical analysis } \\ \text { 7-8/2017 } & 2 \text { month } & \begin{array}{l}\text { Discussion, conclusion and } \\ \text { Recommendation }\end{array}\end{array}$

\subsection{Administrative Design and Ethical Considerations}

To carry out the study, the necessary official permissions were obtained:

1-Approval was obtained from the scientific ethical review committee in community and industrial medicine department and Al-azhar faculty of medicine.

2-Approval obtained for performing the study from Sharkia health directorate and the managers of the chosen family health centers after explaining to them the purpose of the study.

3-An informed oral consent was obtained from geriatric population and family physicians involved in the study after explaining to them the purpose of the study.

\subsection{Limitations of the Study}

1. Rare information about comprehensive geriatric care in Sharkia governorate.

2. Little cooperation from the family physicians during study conduction. 
3. Some geriatric population may discuss in details not related to the study, this may consume very long time during the interview.

\section{Results}

Table 1 shows that a total of 630 elderly persons included in the study $327(51.9 \%)$ were males and 303 (48.1\%) were females. $48.6 \%$ of the studied sample were in the age $60-65$ years while $15.4 \%$ were more than 75 years.

Regarding residences, the majority of the studied population were rural population $(82.5 \%)$. According to educational level, the most of the studied population had primary education $(28.1 \%)$.

As regard marital status, $(74.8 \%)$ were married. Regarding living within family, $(80.3 \%)$ of the studied population were living in families. As regard smoking, (67.9\%) of the studied population were smokers.

Figure 1: Reveals that $(23.9 \%)$ of males reported that their health is good compared with $(11.2 \%)$ of females. While $(56.8 \%)$ of female reported that their health is bad compared with $(51.7 \%)$ of males.

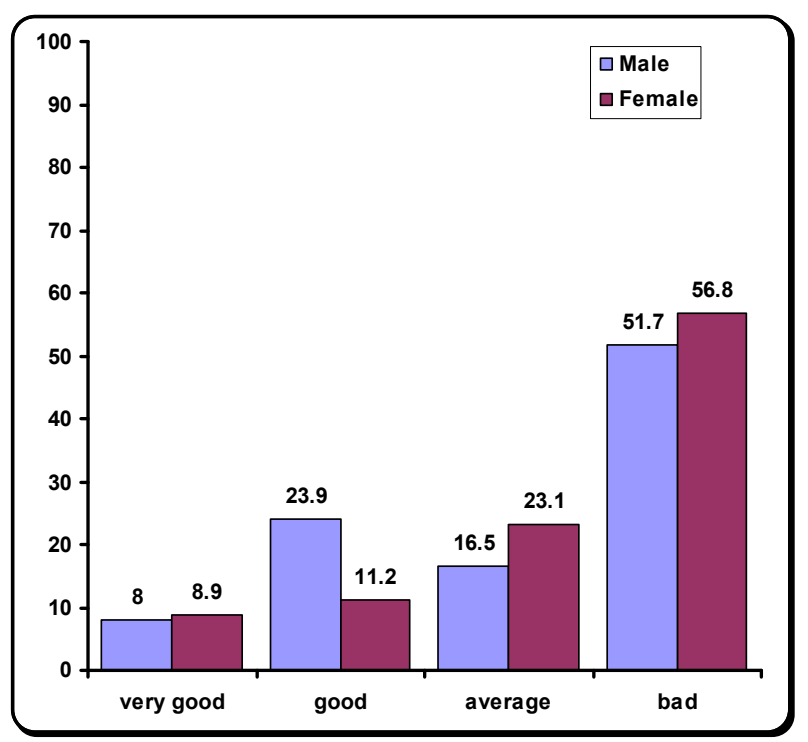

Figure 1. Percent distribution of the studied population according to self perceived general health status.

Table 1. Socio-demographic characteristics of the studied geriatric population. $N=630$.

\begin{tabular}{|c|c|c|c|c|c|c|c|c|c|}
\hline \multirow{3}{*}{ Variable } & & \multicolumn{6}{|l|}{ Sex } & \multirow{2}{*}{\multicolumn{2}{|c|}{ Chi-square }} \\
\hline & & \multicolumn{2}{|c|}{ Male $N=327(51.9 \%)$} & \multicolumn{2}{|c|}{ Female $N=303(48.1 \%)$} & \multicolumn{2}{|c|}{ Total } & & \\
\hline & & $\mathbf{N}$ & $\%$ & $\mathbf{N}$ & $\%$ & $\mathbf{N}$ & $\%$ & $\mathbf{X}^{2}$ & P-value \\
\hline \multirow{5}{*}{ Age (years) } & $60-65$ & 133 & $40.7 \%$ & 173 & $57.1 \%$ & 304 & $48.6 \%$ & \multirow{4}{*}{40.039} & \multirow{4}{*}{$<0.001 *$} \\
\hline & $65-70$ & 131 & $40.1 \%$ & 55 & $18.2 \%$ & 188 & $29.5 \%$ & & \\
\hline & $70-75$ & 21 & $6.4 \%$ & 20 & $6.6 \%$ & 41 & $6.5 \%$ & & \\
\hline & $>75$ & 42 & $12.8 \%$ & 55 & $18.2 \%$ & 97 & $15.4 \%$ & & \\
\hline & & \multicolumn{6}{|c|}{ Mean age $=67.3 \pm 6.6$} & & \\
\hline \multirow{3}{*}{ Residence } & Rural & 270 & $82.6 \%$ & 250 & $82.5 \%$ & 520 & $82.5 \%$ & \multirow{3}{*}{0.000} & \multirow{3}{*}{0.984} \\
\hline & Urban & 57 & $17.4 \%$ & 53 & $17.5 \%$ & 110 & $17.5 \%$ & & \\
\hline & Illiterate & 62 & $19.0 \%$ & 73 & $24.1 \%$ & 135 & $21.4 \%$ & & \\
\hline \multirow{4}{*}{$\begin{array}{l}\text { Level of } \\
\text { Education }\end{array}$} & Read and write & 70 & $21.4 \%$ & 53 & $17.5 \%$ & 123 & $19.5 \%$ & \multirow{4}{*}{33.370} & \multirow{4}{*}{$<0.001^{*}$} \\
\hline & Primary education & 119 & $36.4 \%$ & 58 & $19.1 \%$ & 177 & $28.1 \%$ & & \\
\hline & Secondary education & 57 & $17.4 \%$ & 90 & $29.8 \%$ & 147 & $23.4 \%$ & & \\
\hline & High education & 19 & $5.8 \%$ & 29 & $9.6 \%$ & 48 & $7.6 \%$ & & \\
\hline \multirow{4}{*}{ Marital status } & Single & 14 & $4.3 \%$ & 20 & $6.6 \%$ & 34 & $5.4 \%$ & \multirow{4}{*}{84.152} & \multirow{4}{*}{$<0.001 *$} \\
\hline & Married & 284 & $86.9 \%$ & 187 & $61.7 \%$ & 471 & $74.8 \%$ & & \\
\hline & Widow & 14 & $4.3 \%$ & 89 & $29.4 \%$ & 103 & $16.3 \%$ & & \\
\hline & Divorced & 15 & $4.6 \%$ & 7 & $2.3 \%$ & 22 & $3.5 \%$ & & \\
\hline \multirow{2}{*}{ Staying with } & Alone & 57 & $17.4 \%$ & 67 & $22.1 \%$ & 124 & $19.7 \%$ & \multirow{2}{*}{2.179} & \multirow{2}{*}{0.140} \\
\hline & With family & 270 & $82.6 \%$ & 236 & $77.9 \%$ & 506 & $80.3 \%$ & & \\
\hline \multirow{2}{*}{ Smoking } & No & 138 & $42.2 \%$ & 290 & $95.7 \%$ & 428 & $67.9 \%$ & \multirow{2}{*}{237.823} & \multirow{2}{*}{$<0.001^{*}$} \\
\hline & Yes & 189 & $57.8 \%$ & 13 & $4.3 \%$ & 202 & $32.1 \%$ & & \\
\hline
\end{tabular}

Table 2. Distribution of self reported health problem among the studied population.

\begin{tabular}{|c|c|c|c|c|c|c|c|c|}
\hline \multirow{3}{*}{ Variable } & \multicolumn{6}{|l|}{ Sex } & \multirow{2}{*}{\multicolumn{2}{|c|}{ Chi-square }} \\
\hline & \multicolumn{2}{|l|}{ Male } & \multicolumn{2}{|c|}{ Female } & \multicolumn{2}{|c|}{ Total } & & \\
\hline & $\mathbf{N}$ & $\%$ & $\mathbf{N}$ & $\%$ & $\mathbf{N}$ & $\%$ & $\mathbf{X}^{2}$ & P-value \\
\hline Cataract & 28 & $8.6 \%$ & 78 & $25.7 \%$ & 106 & $16.8 \%$ & 34.119 & $<0.001 *$ \\
\hline Diabetes & 107 & $32.7 \%$ & 124 & $40.9 \%$ & 231 & $36.7 \%$ & 4.558 & $0.033^{*}$ \\
\hline Hypertension & 156 & $47.7 \%$ & 55 & $18.2 \%$ & 211 & $33.5 \%$ & 63.702 & $<0.001 *$ \\
\hline Heart diseases & 13 & $4.0 \%$ & 0 & $0.0 \%$ & 13 & $2.1 \%$ & 17.303 & $<0.001 *$ \\
\hline Respiratory diseases & 93 & $28.4 \%$ & 34 & $11.2 \%$ & 127 & $20.2 \%$ & 30.015 & $<0.001 *$ \\
\hline Musculoskeletal diseases & 27 & $8.3 \%$ & 67 & $22.1 \%$ & 94 & $14.9 \%$ & 24.322 & $<0.001 *$ \\
\hline Psychiatric diseases & 14 & $4.3 \%$ & 0 & $0.0 \%$ & 14 & $2.2 \%$ & 18.656 & $<0.001 *$ \\
\hline Tumors & 35 & $10.7 \%$ & 15 & $5.0 \%$ & 50 & $7.9 \%$ & 7.341 & $0.007 *$ \\
\hline Prostate diseases & 14 & $4.3 \%$ & 0 & $0.0 \%$ & 14 & $2.2 \%$ & 18.656 & $<0.001 *$ \\
\hline
\end{tabular}


Table 2: Shows that the prevalence of self reported diabetes was higher in females $(40.9 \%)$ than males $(32.7 \%)$, while self reported hypertension was higher in males $(47.4 \%)$ than females $(18.2 \%)$, on the other hand self reported musculoskeletal diseases was higher in females $(22.1 \%)$ than males $(8.3 \%)$. These differences were statistically significant.

Table 3. Prevalence of depression among the studied population.

\begin{tabular}{|c|c|c|c|c|c|c|c|c|}
\hline \multirow{3}{*}{ Depression } & \multicolumn{6}{|l|}{ Sex } & \multirow{2}{*}{\multicolumn{2}{|c|}{ Chi-square }} \\
\hline & \multicolumn{2}{|c|}{ Male } & \multicolumn{2}{|c|}{ Female } & \multicolumn{2}{|c|}{ Total } & & \\
\hline & $\mathbf{N}$ & $\%$ & $\mathbf{N}$ & $\%$ & $\mathbf{N}$ & $\%$ & $X^{2}$ & P-value \\
\hline Not depressed & 169 & $51.7 \%$ & 100 & $33.0 \%$ & 269 & $42.7 \%$ & 22.608 & $<0.001^{*}$ \\
\hline Depressed & 158 & $48.3 \%$ & 203 & $67.0 \%$ & 361 & $57.3 \%$ & 22.000 & -0.001 \\
\hline
\end{tabular}

Table 3: Shows that $(48.3 \%)$ of the males are suffering from depression compared with $(67 \%)$ of females. This difference was statistically significant.

Table 4. Sociodemographic characteristics of the studied family physicians.

\begin{tabular}{lll}
\hline Socio-demographic Characteristics of physicians & $\mathbf{N}=\mathbf{5 2}$ & $\mathbf{\%}$ \\
\hline Age & & 63.5 \\
$\leq 30$ & 33 & 36.5 \\
$>30$ & 19 & 40.4 \\
Sex & & 59.6 \\
Male & 21 & 63.5 \\
Female & 31 & 36.5 \\
Residence & 33 & 30.8 \\
Rural & 19 & 69.2 \\
Urban & & 57.7 \\
Post-graduate training & 16 & 42.3 \\
Yes & 36 & 38.5 \\
Years of experience & & 61.5 \\
$>1$ & 30 & 22 \\
$>1$ & 20 & \\
Postgraduate studies & 22 & \\
No & 32 & \\
Yes & & \\
\hline
\end{tabular}

Table 4 shows that nearly two thirds $(63.5 \%)$ of the studied family physicians had 30 years old or less, females were more than males $(59.6 \%$ versus $40.4 \%)$, high percent $(63.5 \%)$ of the studied physicians were living in rural areas, $(69.2 \%)$ had post graduate training, $(57.7 \%)$ had less than one year of experience in family medicine and $(61.5 \%)$ had postgraduate studies.

Table 5. Distribution of the level of knowledge of the studied family physicians about comprehensive geriatric care.

\begin{tabular}{|c|c|c|c|c|c|c|}
\hline \multirow{3}{*}{ Items of knowledge } & \multicolumn{4}{|c|}{ Knowledge } & \multirow{2}{*}{\multicolumn{2}{|c|}{ Chi-square }} \\
\hline & \multicolumn{2}{|c|}{ Inadequate } & \multicolumn{2}{|c|}{ Adequate } & & \\
\hline & $\mathbf{N}$ & $\%$ & $\mathbf{N}$ & $\%$ & $\mathbf{X}^{2}$ & P-value \\
\hline Geriatric problems & 30 & $57.7 \%$ & 22 & $42.3 \%$ & 1.231 & 0.267 \\
\hline Physical problems & 12 & $23.1 \%$ & 40 & $76.9 \%$ & 15.077 & $0.000^{*}$ \\
\hline Elderly abuse & 37 & $71.2 \%$ & 15 & $28.8 \%$ & 9.308 & $0.002 *$ \\
\hline Nutritional problems & 22 & $42.3 \%$ & 30 & $57.7 \%$ & 1.231 & 0.267 \\
\hline Psychological problems & 25 & $48.1 \%$ & 27 & $51.9 \%$ & 0.077 & 0.782 \\
\hline Geriatric assessment & 36 & $69.2 \%$ & 16 & $30.8 \%$ & 7.692 & $0.006^{*}$ \\
\hline Health records & 45 & $86.5 \%$ & 7 & $13.5 \%$ & 27.769 & $0.000 *$ \\
\hline Family health center services & 16 & $30.8 \%$ & 36 & $69.2 \%$ & 7.692 & $0.006^{*}$ \\
\hline Functional status assessment & 37 & $71.2 \%$ & 15 & $28.8 \%$ & 9.308 & $0.002 *$ \\
\hline Food guide pyramid of the elderly & 33 & $63.5 \%$ & 19 & $36.5 \%$ & 3.769 & $0.05^{*}$ \\
\hline Nutrient supplementation & 19 & $36.5 \%$ & 33 & $63.5 \%$ & 3.769 & $0.05^{*}$ \\
\hline Immunization & 45 & $86.5 \%$ & 7 & $13.5 \%$ & 27.769 & $0.000 *$ \\
\hline Health education of the elderly & 23 & $44.2 \%$ & 29 & $55.8 \%$ & 0.692 & 0.405 \\
\hline Drug compliance & 35 & $67.3 \%$ & 17 & $32.7 \%$ & 6.231 & $0.013^{*}$ \\
\hline Adverse reaction to drugs & 26 & $50.0 \%$ & 26 & $50.0 \%$ & 0.000 & 1.000 \\
\hline Drug prescription & 38 & $73.1 \%$ & 14 & $26.9 \%$ & 11.077 & $0.001^{*}$ \\
\hline
\end{tabular}

Table 5 shows that $(76.9 \%)$ of the studied family physicians have adequate knowledge about physical problems of the elderly population, (69.2\%) have adequate knowledge about family health center services, (63.5\%) have adequate knowledge about nutrient supplementation and (57.7\%) adequate knowledge about nutritional problems of geriatric while only (13.5\%) have adequate knowledge about health records and immunization of the elderly population. 
Table 6. Determinants of knowledge of family physicians about comprehensive geriatric care.

\begin{tabular}{|c|c|c|c|c|c|c|c|c|c|}
\hline \multirow{3}{*}{ Level of knowledge } & & \multicolumn{6}{|c|}{ Knowledge } & \multirow{2}{*}{\multicolumn{2}{|c|}{ Chi-square }} \\
\hline & & \multicolumn{2}{|c|}{ Inadequate } & \multicolumn{2}{|c|}{ Adequate } & \multicolumn{2}{|c|}{ Total } & & \\
\hline & & $\mathbf{N}$ & $\%$ & $\mathbf{N}$ & $\%$ & $\mathbf{N}$ & $\%$ & $\mathbf{X}^{2}$ & P-value \\
\hline \multirow[b]{2}{*}{ Sex } & Male & 18 & $85.7 \%$ & 3 & $14.3 \%$ & 21 & $40.4 \%$ & \multirow{2}{*}{5.816} & \multirow[b]{2}{*}{$0.016^{*}$} \\
\hline & Female & 17 & $54.8 \%$ & 14 & $45.2 \%$ & 31 & $59.6 \%$ & & \\
\hline \multirow{2}{*}{ Age (years) } & $\leq 30$ & 18 & $54.5 \%$ & 15 & $45.5 \%$ & 33 & $63.5 \%$ & \multirow{2}{*}{5.192} & \multirow{2}{*}{$0.022 *$} \\
\hline & $>30$ & 17 & $89.5 \%$ & 2 & $10.5 \%$ & 19 & $36.5 \%$ & & \\
\hline \multirow{2}{*}{ Post graduate Training } & No & 11 & $68.7 \%$ & 5 & $31.3 \%$ & 16 & $30.8 \%$ & \multirow{2}{*}{0.022} & \multirow{2}{*}{0.882} \\
\hline & Yes & 24 & $66.7 \%$ & 12 & $33.3 \%$ & 36 & $69.2 \%$ & & \\
\hline \multirow{2}{*}{ Period of experience (years) } & $\leq 1$ & 20 & $66.7 \%$ & 10 & $33.3 \%$ & 30 & $57.7 \%$ & \multirow{2}{*}{0.013} & \multirow{2}{*}{0.908} \\
\hline & $>1$ & 15 & $68.2 \%$ & 7 & $31.8 \%$ & 22 & $42.3 \%$ & & \\
\hline \multirow{2}{*}{ Postgraduate studies } & No & 14 & $70 \%$ & 6 & $30 \%$ & 20 & $38.5 \%$ & \multirow{2}{*}{0.001} & \multirow{2}{*}{0.981} \\
\hline & Yes & 21 & $65.6 \%$ & 11 & $34.4 \%$ & 32 & $61.5 \%$ & & \\
\hline
\end{tabular}

Table 6 Shows that the level of adequate knowledge was higher among female physicians $(45.2 \%)$ than male physicians $(14.3 \%)$, it was higher among physicians less than 30 years $(45.5 \%)$ than physicians more than 30 years $(10.5 \%)$ and these differences were statistically significant. It also shows that the level of adequate knowledge was higher among physicians who had post graduate training in family medicine $(33.3 \%)$ than physicians who had not post graduate training (31.3\%), it was higher among physicians with period of experience less than one year in family medicine (33.3\%) than physicians with period of experience more than one year $(31.8 \%)$, it was higher among physicians who had post graduate studies in family medicine $(34.4 \%)$ than physicians who had not post graduate studies $(30 \%)$ and these differences were not statistically significant.

Table 7. Distribution of the level of performance of the studied family physicians about comprehensive geriatric care.

\begin{tabular}{|c|c|c|c|c|c|c|}
\hline \multirow{3}{*}{ Items of performance of physicians } & \multicolumn{4}{|c|}{ Performance } & \multirow{2}{*}{\multicolumn{2}{|c|}{ Chi-square }} \\
\hline & \multicolumn{2}{|c|}{ Inadequate } & \multicolumn{2}{|c|}{ Adequate } & & \\
\hline & $\mathbf{N}$ & $\%$ & $\mathbf{N}$ & $\%$ & $\mathbf{X}^{2}$ & P-value \\
\hline Personal history & 39 & $75.0 \%$ & 13 & $25.0 \%$ & 13.000 & $0.000 *$ \\
\hline Past history & 41 & $78.8 \%$ & 11 & $21.2 \%$ & 17.308 & $0.000^{*}$ \\
\hline Present history & 46 & $88.5 \%$ & 6 & $11.5 \%$ & 30.769 & $0.000 *$ \\
\hline Social history & 41 & $78.8 \%$ & 11 & $21.2 \%$ & 17.308 & $0.000^{*}$ \\
\hline Family history & 41 & $78.8 \%$ & 11 & $21.2 \%$ & 17.308 & $0.000 *$ \\
\hline Functional status assessment & 42 & $80.8 \%$ & 10 & $19.2 \%$ & 19.692 & $0.000 *$ \\
\hline Mental and psychological status assessment & 40 & $76.9 \%$ & 12 & $23.1 \%$ & 15.077 & $0.000 *$ \\
\hline Immunization status assessment & 47 & $90.4 \%$ & 5 & $9.6 \%$ & 33.923 & $0.000 *$ \\
\hline Referral & 44 & $84.6 \%$ & 8 & $15.4 \%$ & 24.923 & $0.000 *$ \\
\hline General examination & 45 & $86.5 \%$ & 7 & $13.5 \%$ & 27.769 & $0.000 *$ \\
\hline Abdominal examination & 39 & $75.0 \%$ & 13 & $25.0 \%$ & 13.000 & $0.000 *$ \\
\hline Communication follow up & 42 & $80.8 \%$ & 10 & $19.2 \%$ & 19.692 & $0.000^{*}$ \\
\hline Health education & 46 & $88.5 \%$ & 6 & $11.5 \%$ & 30.769 & $0.000 *$ \\
\hline Counseling & 39 & $75.0 \%$ & 13 & $25.0 \%$ & 13.000 & $0.000 *$ \\
\hline
\end{tabular}

Table 7 shows that $(25 \%)$ of the studied family physicians have adequate performance in taking personal history, abdominal examination and counseling of the elderly population, while only (9.6\%) have adequate performance in assessment of immunization status of the elderly population.

Table 8. Determinants of performance of family physicians about comprehensive geriatric care.

\begin{tabular}{|c|c|c|c|c|c|c|c|c|c|}
\hline \multirow{3}{*}{ Level of performance } & & \multicolumn{6}{|c|}{ Performance } & \multirow{2}{*}{\multicolumn{2}{|c|}{ Chi-square }} \\
\hline & & \multicolumn{2}{|c|}{ Inadequate } & \multicolumn{2}{|c|}{ Adequate } & \multicolumn{2}{|c|}{ Total } & & \\
\hline & & $\mathbf{N}$ & $\%$ & $\mathbf{N}$ & $\%$ & $\mathbf{N}$ & $\%$ & $\mathbf{X}^{2}$ & P-value \\
\hline \multirow{2}{*}{ Sex } & Male & 17 & $81 \%$ & 4 & $19 \%$ & 21 & $40.4 \%$ & \multirow{2}{*}{0.054} & \multirow{2}{*}{0.816} \\
\hline & Female & 23 & $74.2 \%$ & 8 & $25.8 \%$ & 31 & $59.6 \%$ & & \\
\hline \multirow{2}{*}{ Age (years) } & $\leq 30$ & 24 & $72.7 \%$ & 9 & $27.3 \%$ & 33 & $63.5 \%$ & \multirow{2}{*}{0.934} & \multirow{2}{*}{0.334} \\
\hline & $>30$ & 16 & $84.2 \%$ & 3 & $15.8 \%$ & 19 & $36.5 \%$ & & \\
\hline \multirow{2}{*}{ Post graduate Training } & No & 15 & $93.7 \%$ & 1 & $6.3 \%$ & 16 & $30.8 \%$ & \multirow{2}{*}{4.384} & \multirow{2}{*}{$0.036^{*}$} \\
\hline & Yes & 25 & $69.4 \%$ & 11 & $30.6 \%$ & 36 & $69.2 \%$ & & \\
\hline \multirow{2}{*}{ Period of experience } & $\leq 1$ & 19 & $63.3 \%$ & 11 & $36.7 \%$ & 30 & $57.7 \%$ & \multirow{2}{*}{7.433} & \multirow{2}{*}{$0.017 *$} \\
\hline & $>1$ & 21 & $95.5 \%$ & 1 & $4.5 \%$ & 22 & $42.3 \%$ & & \\
\hline \multirow{2}{*}{ Postgraduate studies } & No & 18 & $90 \%$ & 2 & $10 \%$ & 20 & $38.5 \%$ & \multirow{2}{*}{3.428} & \multirow{2}{*}{0.064} \\
\hline & Yes & 22 & $68.7 \%$ & 10 & $31.3 \%$ & 32 & $61.5 \%$ & & \\
\hline
\end{tabular}


Table 8 Shows that the level of adequate performance was higher among female physicians $(25.8 \%)$ than male physicians (19\%), it was higher among physicians less than 30 years $(27.3 \%)$ than physicians more than 30 years $(15.8 \%)$, it was higher among physicians who had post graduate studies $(31.3 \%)$ than physicians who had not post graduate studies $(10 \%)$ and these differences were not statistically significant. It also shows that the level of adequate performance was higher among physicians who had post graduate training in family medicine $(30.6 \%)$ than physicians who had not post graduate training $(6.3 \%)$, it was higher among physicians with period of experience less than one year in family medicine $(36.7 \%)$ than physicians with period of experience more than one year (4.5\%) and these differences were statistically significant.

\section{Discussion}

This study was a cross sectional study. It was conducted in 9 accredited family health centers in Sharkia governorate for one year. The family health centers were selected by stratified random sampling from health centers of Sharkia governorate. The sample included 630 elderly person and 52 family physicians. The aim of this study was to improve the health of geriatrics through:

1. To identify health problems among the studied geriatric population in Sharkia governorate.

2. To illustrate the relation between health problems and the socio-demographic characteristics of the studied geriatric population.

3. To determine the level of the family physicians' knowledge and practice of comprehensive geriatric care in Sharkia governorate.

4. To identify the determinants of level of family physicians' knowledge and practice of comprehensive geriatric care.

I-Characteristics of studied geriatric population

This study revealed that a total of 630 elderly persons included in the study $327(51.9 \%)$ were males and 303 $(48.1 \%)$ were females, the highest percent of the studied geriatric population $(48.6 \%)$ were in the age group between 60 and 65 years and the majority of them $(82.5 \%)$ were of rural residence (Table 1).

Regarding the educational level of the studied population, the results of this study showed that $(28.1 \%)$ of the studied geriatric population had primary education, (23.3\%) had secondary education, $(21.4 \%)$ were illiterates, higher educational level was $(7.6 \%)$, those who are reading and writing were (19.5\%) (Table 1).

In USA Current Population Survey, Annual Social and Economic Supplement, [13] showed that the educational level of the older, population is increasing. Between 1970 and 2010, the percentage of older persons who had completed high school rose from $28 \%$ to $79.5 \%$, about $22.5 \%$ in 2010 had a bachelor's degree or higher.

Regarding marital status this study revealed that widows much higher than widowers $(29.4 \%$ versus $4.3 \%)$. The great difference between widow males and females may be due to females live longer so more female widows are present. Married men were much higher than women $(86.9 \%$ versus $61.7 \%)$. This is due to the likelihood of marriage after divorce or widowhood is much higher among males than females (Table 1).

According to national elderly health survey in Oman, widow was (29.7\%), male (7.4\%), female (54.1\%) [14].

This study revealed that the percent of geriatric population living alone was $(19.7 \%)$ and it was higher among females (22.1\%) than males $(17.4 \%)$ (Table 1). In Oman percent of person living alone was $6.8 \%$ which is lower than our study and this indicated that the social and familial support in Arab countries like Oman was better than Egypt [14].

The results of the present study revealed that only $(8.4 \%)$ of elderly population reported that their health is very good, $(17.8 \%)$ reported that their health is good, $(19.7 \%)$ reported average health, while $(54.1 \%)$ of elderly population reported that their health is bad (Figure 1).

This was in consistent with the result of national elderly health survey in Oman that revealed that $9.2 \%$ of Elderly population reported that their health is "very good, and 37.8 percent reported that their health is "good. On the other side, 2.3 Percent reported "very bad" and 12.8 percent reported "bad" [14].

Regarding self-reported health problems among the studied elderly population (Table 2), this study showed that the prevalence of cataract was $(16.8 \%)$ among elderly population. This was consistent with result of Surckha et al., [15] that showed that eye problems were $(27.7 \%)$ of elderly population and Kavita et al., [16] that showed that eye problems were $(19.6 \%)$.

Diabetes mellitus was the most prevalent health problem in this study $(36.7 \%)$. It was higher in females $(40.9 \%)$ than males $(32.7 \%)$ (Table 2).

This was consistent with the result of a national community based survey in the Saudi Arabia which found that the prevalence of diabetes among elderly population aged 60-70 years was (36.5\%) [17] and with the results of Ibrahim et al., [18] which found the prevalence of diabetes mellitus among study population was $(36 \%)$.

Hypertension was the second most prevalent health problem in this study (33.5\%) (Table 2). It was higher in males $(47.7 \%)$ than females $(18.2 \%)$ This was consistent with a study conducted by Kumar et al., [19] that found that prevalence of hypertension was (44.9\%). Similar results were reported by Bhatia et al., [20].

In India Surckha et al., [15] revealed that prevalence of hypertension in elderly persons was $(41.4 \%)$ which was consistent with the results of our study. However study done by Jadhav et al., [3] revealed lower prevalence of hypertension among elderly $(21.6 \%)$.

The prevalence of respiratory problems among the studied population in our study was $(20.2 \%)$ (Table 2$)$. This was lower than the results reported by Kavita et al., [16] which 
revealed that prevalence of respiratory diseases among elderly were (36\%) comparable to $(9.4 \%)$ findings of [21].

Regarding musculoskeletal problems (Table 2), this study revealed that $(14.9 \%)$ of the studied elderly population suffered musculoskeletal problems. It was higher in females $(22.1 \%)$ than males $(8.3 \%)$. This is in consistent with Surekha et al., [15] which revealed that musculoskeletal problems were present in $(36.8 \%)$ of elderly people.

The present study showed that the prevalence of depression among geriatric was (57.3\%) (Table 3). This study found that depression was more prevalent among females than males (Table 3 ). This result was supported by Wang et al., [22] who stated that women have a high prevalence of depression than men across generations and cultures.

The sex differences the prevalence of depression, first become apparent more in females in early adolescence continued into the 60 years and older age groups. In addition, most studies have shown that women are more exposed to risk factors for depression, such financial difficulties, social isolation, low education and functional disability [23].

II-Characteristics of studied family physicians

The results of this study showed that $(63.5 \%)$ of the studied family physicians were less than 30 years, (59.6) were females, $(63.5 \%)$ were of rural residence, $(69.2 \%)$ had post graduate training, $(57.7 \%)$ had less than one year of experience in family medicine and $(61.5 \%)$ had postgraduate studies (Table 4).

Assessment of the knowledge of family physicians

Regarding the level of knowledge of family physicians about items of comprehensive geriatric care, this study showed that the most of physicians had adequate level of knowledge as regards physical problems, nutritional problems, psychological problems, family health centers services, nutrient supplementation, health education of the elderly and adverse reactions to drugs. But most of the studied family physicians had inadequate level of knowledge regarding geriatric health problems, elderly abuse, comprehensive geriatric assessment, health records, functional status assessment, food guide pyramid of the elderly, immunization of the elderly, drug compliance and drug prescription (Table 5).

This result is consistent with the study of Almogue et al., [24] which showed unsatisfactory level of knowledge of physicians in elderly abuse. This result is also consistent with the study of Mowe et al., [25] which showed unsatisfactory level of knowledge of physicians in food guide pyramid of the elderly. This result is also consistent with the study of Pavia et al., [26] in Italy which showed unsatisfactory level of knowledge of physicians in immunization of the elderly. This may be due to lack of regular training and educational sessions for the newly graduated and family physicians in the family health centers and lack of interest of many physicians with the geriatric care services.

Relation between socio-demographic characteristics of family physicians and level of knowledge.

The results of the current study found significant relation between sex and level of knowledge of physicians, as adequate knowledge was higher among the female physicians $(45.2 \%)$ than the male physicians $(14.3 \%)$ (Table 6). The study of Ranjbar and Bavafa, [27] also found that the female physicians had the higher percentage of good level of knowledge with significant difference than male physicians, and this may be explained as the female physicians are more curious about geriatric care and they are more familiar with the customers than male physicians. Also the same result was found in the study of Arzu, [28] who found statistical significant relationship between the knowledge of physicians and their sex as female physicians had more information than male physicians. But the study of Akl, [29] found no significant differences in the knowledge of family physicians in relation to sex.

The results of our study reported significant relation between age and level of knowledge of physicians as adequate knowledge was higher among the physicians less than 30 years $(45.5 \%)$ than the physicians more than 30 years $(10.5 \%)$ (Table 6). This can be explained by that the newly graduated physicians only had fresh information and more adapted to the new protocols of practice of family medicine. This result is inconsistent with the study of NourEldein et al., [30] in Egypt which found that there was statistical significant relationship between the knowledge of physicians and their age and about $(75 \%)$ of physicians who did not passed the knowledge assessment were less than 30 years old.

The present study revealed that there is no significant difference between level of knowledge and post graduate training in family medicine, as adequate knowledge was higher among the physicians who had post graduate training in family medicine $(33.3 \%)$ than physicians who had not post graduate training in family medicine $(31.3 \%$ ) (Table 6$)$.

This result is consistent with the study of Claire, [31] which assessed the level of knowledge by pre- and posttraining tests and found that all pre-training test results were relatively low; providers answered about half of all questions correctly. The largest increase in providers' knowledge was in post-training tests ( $45 \%$ increases in correct answers). This may be due to the effect of the course of training which leads to refreshment of information and it concentrates on the practical application of knowledge as recognizing signs and symptoms and providing treatment.

The results of this study clarified that adequate knowledge was higher among the physicians with period of experience less than 1 year in family medicine $(33.3 \%)$ than the physicians with period of experience more than 1 year in family medicine $(31.8 \%)$ and no significant relation between period of experience and level of knowledge of physicians (Table 6).

This result is consistent with the results of the study which was conducted by Ranjbar and Bavafa, [27] who found that adequate level of knowledge is higher in physicians with less years of experience and also stated that older family physicians did not use WHO protocols because these protocols are new and recently introduced and they were not familiar with them according to their own statements, while 
young family physicians and recently graduated practitioners have learned these protocols and some of them are actually working with these protocols in health care centers.

Also this result is consistent with the results of the study conducted by Abolfotouh, [32] who found that experience was not significantly associated with the level of knowledge. This might reflect the necessity of continuing medical education programs for all physicians irrespective of their previous experience. But this result is inconsistent with the study of Akl, [29] who found that the majority of physicians with 10 years of practice or more had adequate knowledge level.

The results of our study declared that there is no significant difference between level of knowledge and post graduate studies in family medicine although adequate knowledge was higher among physicians who had post graduate studies in family medicine $(34.4 \%)$ than physicians who had not post graduate studies (30\%) (Table 6). This may explained as refreshment of physicians knowledge by post graduate educational sessions. This result is consistent with the study of Akl, [29] in Egypt and Ranjbar and Bavafa [27] and which found no significant difference between physicians' knowledge and their qualification level.

This result is in consistent with the results of the study of NourEldein et al., [30] which found that there was statistical significant relationship between the knowledge of physicians and their qualifications and better scores of knowledge were found among qualified physicians.

Assessment of performance of family physicians

Assessment of the level of performance of the studied sample of family physicians declared that the most of family physicians had inadequate level of performance as regard physicians performance during dealing with geriatric patient (Table 7). This result is inconsistent with the results of the study of Goulet et al., [33] in France who found that the overall clinical performance of family physicians is excellent.

In this study, the bad performance of family physicians during dealing with geriatric patients may be due to little number of physicians versus high attendance rate of customers which doesn't save much time for each patient. Also the bad performance of family physicians during dealing with geriatric patients may be due to lack of post graduate training on examination, counseling and health education and lack of interest of many physicians towards the geriatric care services.

Relation between socio-demographic characteristics of family physicians and level of performance

The results of the present study illustrated that there was no significant relation between sex of family physicians and level of performance of physicians but adequate level of performance was higher in female physicians $(25.8 \%)$ than male physicians (19\%) (Table 8). This result is inconsistent with the results of the study of NourEldein, [30] in Egypt which found that there is significant relation between sex and level of performance of physicians.

The results of this study found no significant relation between age of family physicians and the level of performance of family physicians, but adequate level of performance was higher among family physicians less than 30 years old $(27.3 \%)$ than family physicians more than 30 years old (15.8\%) (Table 8 ).

This result is in accordance with the study of Van Harrison et al., [34] which found that there was no statistical significant relationship between the performance of physicians and their age and younger physicians had more satisfactory performance than older physicians.

The results of the current study revealed significant relation between post graduate training in family medicine and level of performance of family physicians, as adequate level of performance was higher among physicians who had post graduate training in family medicine (30.6\%)than physicians who had not post graduate training in family medicine $(6.3 \%)$ (Table 8$)$.

This result is consistent with the results of the study of Akl, [29] which reported that adequate level of performance was higher among physicians who had post graduate training.

The results of the present study revealed that there is significant relation between period of experience in family medicine and level of performance of family physicians, as adequate performance was higher among the physicians with period of experience less than 1 year in family medicine $(36.7 \%)$ than the physicians with period of experience more than 1 year in family medicine $(4.5 \%)$ (Table 8$)$. This result is in accordance with the results of the study conducted by Choudhry et al., [35] which reported decreasing performance of physicians with increasing years in practice.

The results of our study found insignificant relation between post graduate studies in family medicine and level of performance of physicians, but adequate level of performance was observed among physicians who had post graduate studies in family medicine $(31.3 \%)$ compared with $(10 \%)$ of physicians who had not post graduate studies in family medicine (Table 8 ). This result is consistent with the study of Akl, [29] which found that there was no statistical significant relationship between the performance of physicians and their post graduate studies and about $(66 \%)$ of physicians with post graduate degrees had adequate practice level.

\section{Conclusion}

According to the results of this study and interpretation of these results, it could be concluded that:

I- Regarding geriatric population:

1. The percentage of those who live alone was higher in females than males.

2. The more prevalent self reported morbidities were, diabetes mellitus, hypertension and respiratory disease. The prevalence of self reported diabetes was higher in females than males, while self reported hypertension was higher in males than females, on the other hand self reported musculoskeletal diseases was higher in females than males.

3. Prevalence rate of depression among the studied 
geriatric population was $(57.3 \%)$ and it was more prevalent among females than males.

II- Regarding family physicians:

1. Most of family physicians had adequate level of knowledge as regards physical problems, nutritional problems, psychological problems, family health centers services, nutrient supplementation, health education of the elderly and adverse reactions to drugs. But most of them had inadequate level of knowledge regarding elderly abuse, comprehensive geriatric assessment, health records, functional status assessment, food guide pyramid of the elderly, immunization of the elderly, drug compliance and drug prescription.

2. Adequate knowledge was higher among female physicians, physicians less than 30 years old, physicians with period of experience less than 1 year in family medicine, and also among physicians who had post graduate training and post graduate studies in family medicine.

3. Most of family physicians had inadequate level of performance as regard physicians performance during dealing with geriatric patient.

4. Adequate performance was higher among female physicians, physicians less than 30 years old, physicians with period of experience less than 1 year in family medicine, and also among physicians who had post graduate training and post graduate studies in family medicine.

\section{Recommendations}

Based on the results of this study and the conclusions, we can recommend the following:

I- Regarding geriatric population:

1. Maintenance of the family role in supporting elderly population is fundamental.

2. The study highlighted a high prevalence of morbidity and health related problems in old age group. We need to promote geriatric health care services, regular health check up and social support by people.

3. Screening programs for chronic diseases, especially for diabetes and hypertension, is highly recommended among elderly population to decrease disability.

4. Actions include educational programs, exercise, removing hazards and obstacles from elderly environment.

5. Mental health of the elderly should receive more attention. The findings of the present study reflect the importance of providing mental health care for elderly.

II- Regarding family physicians:

1. Develop check lists for assessment of both knowledge and performance of family physicians regarding comperhensive geriatric care.

2. Continuous training of family physicians specially in comperhensive geriatric care for providing high quality of care for elderly population.

a. Continuous updating of ministry of health guidelines according to evidence based medicine.

b. Family physicians should follow ministry of health practical guidelines for family physicians for good care of the geriatric population.

\section{References}

[1] WHO (2015): What are the public health implications of global ageing? http://www.who.int/features/qa/42/en/index.html.

[2] El-Zanaty, F. and Ann Way (2009): Egypt Demographic and Health Survey 2008, Cairo, Egypt: Ministry of Health.

[3] Jadhav, V. S.; Mundada, V. D. and Gaikwad, A. V. (2012): A study of morbidity profile of geriatric population in the field practice area of rural health training centers. Medical college, AURANGABAD, IOSR Journal of Pharmacy, Mar.-Apr. 2012, Vol. 2(2) p: 184-188.

[4] Joshi, K.; Kumar, R. and Avasthi, A. (2003): Morbidity profile and its relationship with disability and psychological distress among elderly people in Northern India. International Journal of Epidemiology 2003; 32:978-987.

[5] Ellis, G.; Whitehead, M. A.; O'Neill, D.; Langhorne, P. and Robinson, D. (2011): Comprehensive geriatric assessment for older adults admitted to hospital. Cochrane Database of Systematic Reviews, Issue 7. Art. No.: CD006211. DOI.CD006211.pub2.

[6] Boyd, C. M. and Fortin M. (2011): Future of multi morbidity research: How should understanding of multi morbidity inform health system design? Public Health Reviews Volume 32, pages $451-474$.

[7] Reuben, D. B.; Frank, J. C.; Hirsch, S. H.; McGuigan, K. A. and Maly, R. C. (2005): A randomized clinical trial of outpatient comprehensive geriatric assessment coupled with an intervention to increase adherence to recommendations. J Am Geriatr Soc; 47: 269-276.

[8] Karle, M.; Robert, G.; Zylstra, E. D. and John, B. (2007): The Geriatric Patient: A Systematic Approach to Maintaining Health. University of Tennessee College of Medicine, Chattanooga, Tennessee Am Fam Physician. Volume 61, Issue 4, pages 1089 -1104.

[9] Xakellis, G. C. (2008): Who provides care to Medicare beneficiaries and what settings do they use? Am Board Fam Pract. Volume 17, Issue 5, pages 384-387.

[10] Landefeld, C. S. (2003): Improving health care for older persons. Ann Intern Med. Volume 139, Issue 5, pages 421424.

[11] Elsawy, B. and Kime, H. (2011): The Geriatric Assessment Methodist Charlton Medical Center, Dallas, Texas, Am Fam Physician. Volume 83, Issue 1, pages 48-56.

[12] Practice guideline for family physician (2000): ministry of health and population, Egypt, volume $1 \&$ Volume 3.

[13] Current Population Survey, Annual Social and Economic supplement (2010): related tables on the U.S. Census Bureau web site. 
[14] NEHS, (2008): National elderly health survey sultanate of Oman, world health survey, directorate of research and studies, directorate general of: planning, Ministry of Health, WHO 2008, www.moh.gov.om.

[15] Surekha, K.; Ruchi, J. and Jayanti, S. (2007): Morbidity profile of elderlypersons. JK Science, April-June 2007; 9 (2); 87-89.

[16] Kavita, B.; Bipin, P. and Geeta, K. (2011): study of health profile of resident of Geriatric homein Ahmed Abad district, National Journal of Community Medicine Vol 2 Issue 3 OctDec 2011, p378-p382.

[17] Al-Nozha, M. M.; Al-Maatouq, M. M. and Al-Mazron, Y. Y. (2004): Diabetes mellitus in Saudi Arabia Med J 2004; 25(11): 03-10.

[18] Ibrahim, N. K.; Ghabrah, T. M. and Qadi, M. (2008): Morbidity profile of elderly attended/ admitted in Jeddah health facilities, Saudi Arabia, Department of Family and community Medicine, king Abdul-Aziz University, Jeddah, Kingdom of Saudi Arabia.

[19] Kumar, R.; Ahlawat, S. K. and Singh, M. M, (2000): Time trends in prevalence of risk factors of cardiovascular diseases in Chandigarh. LAPSM' 3rd conference (NZ) Chandigarh.

[20] Bhatia, S. P.; Swami, H. M. and Thakur, J. S. (2007): A study of health problems and Loneliness Among the elderly in Chandigrah, IJCM, OCT 2007; 32, (4); 255-258.

[21] Prakash, R.; Choudhary, S. K. and Singh, U. S. (2004):A Study of Morbidity Pattern among Geriatric Population in an Urban Area of Udaipur, Rajasthan. UCM. 2004; 29 (1): 35-40.

[22] Wang, J. K.; Su, T. P. and Chou, P. (2010): Sex differences in prevalence and risk indicators of geriatric depression: the Shih-Pai community based survey. Journal of the Formosan Medical Association, 2010, 109:345-353.

[23] Eman, M. and Mohamed, A. (2011):Depression among elderly attending geriatric clubs in Assiut City, Egypt, Journal of American Science, 2011: 7 (11).

[24] Almogue, A.; Weiss, A.; Marcus, E. and Beloosesky, Y. (2010): Attitudes and knowledge of medical and nursing staff toward elder abuse. Arch GerontolGeriatr; 51 (1): 86-91.

[25] Mowe, M.; Bosaeus, I.; Hojgaard, H. and Kondrup, J. (2010): Insufficient nutritional knowledge among health care workers? Clinical Nutrition.; 27:196-202.

[26] Pavia, M.; Foresta, M. R.; Carbone, V. and Angelillo, I. F.
(2010): Influenza and pneumococcal immunization in the elderly: knowledge, attitudes, and practices among general practitioners in Italy. Public Health; 117 (3): 202-227.

[27] Ranjbar, S. A. and Bavafa, B. (2007): Physicians' Knowledge Regarding Nutritional Management in Children with Diarrhea: a Study in Kerman, Iran (I. R.), Pakistan Journal of Nutrition 6 (6): 638-640.

[28] Arzu, U.; Cobek, P. U.; Alibaş, H.; Kılıç, I.; Sari, M.; Karakoç, E. and Akbarov, A. (2008): doctors knowledge level and attitudes concerning avian influenza, Marmara Medical Journal; 21 (2); 118-126.

[29] Akl, O. A.; Khairy, A. E.; Abdel-Aal, N. M.; Deghedi, B. S. and Amer, Z. F. (2006): Knowledge, Attitude, Practice and Performance of Family Physicians Concerning Holistic Management of Hypertension, J. Egypt Public Health Assoc. Vol. 81 No. 5.

[30] NourEldein, H.; Mansour, N. and Mohamed, S. (2013): Knowledge, Attitude and Practice of Family Physicians Regarding Smoking Cessation Counseling in Family Practice Centers, Suez Canal University, Egypt. J Family Med Prim Care.; 2 (2): 159-163.

[31] Claire, E. H. (2004): Improving Health Care Providers' Knowledge, Attitudes, and Practices in Reproductive Health in Rural Romania, Project Concern International/Romania.

[32] Abolfotouh, M. A.; Soliman, L. A.; Abolfotouh, S. M. and Raafat, M. (2011): Knowledge and Practice of PHC Physicians toward the Detection and Management of Hypertension and Other CVD Risk Factors in Egypt, International Journal of Hypertension, Volume 2011, Article ID 983869,6 pages.

[33] Goulet, F.; Jacques, A.; Gagnon, R.; Racette, P. and Sieber, $W$. (2007): Assessment of family physicians' performance using patient charts: interrater reliability and concordance with chart-stimulated recall interview. Eval Health Prof; 30 (4): 376-392.

[34] Van Harrison, R.; Janz, N. K.; Wolfe, R. A.; Tedeschi, P. J.; Stross, J. K.; Huang, X. and McMahon, L. F. (2003): Characteristics of primary care physicians and their practices associated with mammography rates for older women. Cancer.; 98 (9): 1811-21.

[35] Choudhry, N. K.; Fletcher, R. H. and Soumerai, S. B. (2005): Systematic review: the relationship between clinical experience and quality of health care. Ann Intern Med. 15; 142 (4): $260-73$. 